\title{
VISIR-SAT - A PROSPECTIVE MICRO-SATELLITE BASED MULTI-SPECTRAL THERMAL MISSION FOR LAND APPLICATIONS
}

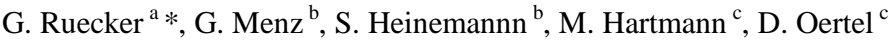

${ }^{\text {a }}$ ZEBRIS GbR, Lipowskystr. 26, 81476Munich, Germany - gruecker@zebris.com

${ }^{\mathrm{b}}$ Center for Remote Sensing of Land Surfaces (ZFL), University of Bonn, Bonn, Germany - g.menz@uni-bonn.de

${ }^{\mathrm{c}}$ Astro- und Feinwerktechnik Adlershof GmbH, Berlin, Germany - M.Hartmann@ astrofein.com

\begin{abstract}
KEY WORDS: Thermal infrared remote sensing, fire detection and characterization, land surface temperature, small satellites,
\end{abstract} convoy missions

\begin{abstract}
:
Current space-borne thermal infrared satellite systems aimed at land surface remote sensing retain some significant deficiencies, in particular in terms of spatial resolution, spectral coverage, number of imaging bands and temperature-emissivity separation. The proposed VISible-to-thermal IR micro-SATellite (VISIR-SAT) mission addresses many of these limitations, providing multi-spectral imaging data with medium-to-high spatial resolution (80m GSD from $800 \mathrm{~km}$ altitude) in the thermal infrared (up to 6 TIR bands, between 8 and $11 \mu \mathrm{m})$ and in the mid infrared ( 1 or 2 MIR bands, at $4 \mu \mathrm{m})$. These MIR/TIR bands will be co-registered with simultaneously acquired high spatial resolution (less than $30 \mathrm{~m}$ GSP) visible and near infrared multi-spectral imaging data. To enhance the spatial resolution of the MIR/TIR multi-spectral imagery during daytime, data fusion methods will be applied, such as the Multi-sensor Multi-resolution Technique (MMT), already successfully tested over agricultural terrain. This image processing technique will make generation of Land Surface Temperature (LST) EO products with a spatial resolution of $30 \times 30 \mathrm{~m}^{2}$ possible. For high temperature phenomena such as vegetation- and peat-fires, the Fire Disturbance Essential Climate Variables (ECV) "Active fire location" and "Fire Radiative Power" will be retrieved with less than $100 \mathrm{~m}$ spatial resolution. Together with the effective fire temperature and the spatial extent even for small fire events the innovative system characteristics of VISIR-SAT go beyond existing and planned IR missions.

The comprehensive and physically high-accuracy products from VISIR-SAT (e.g. for fire monitoring) may synergistically complement the high temperature observations of Sentinel-3 SLSTR in a unique way. Additionally, VISIR-SAT offers a very agile sensor system, which will be able to conduct intelligent and flexible pointing of the sensor's line-of-sight with the aim to provide global coverage of cloud free imagery every 5-10 days with only one satellite (using near real time cloud cover information). VISIRSAT may be flown in convoy with Sentinel-3 and/or Sentinel-2.
\end{abstract}

\section{INTRODUCTION}

\subsection{General Instructions}

Medium-to-high spatial resolution multi-spectral space-borne images in the thermal- and mid-infrared (TIR, MIR) region of the electromagnetic spectrum is required to improve knowledge on the carbon cycle, energy and matter fluxes of land surfaces, wildfire emissions and volcanic outbreaks as well as human activities. Current in-orbit higher spatial resolution TIR sensor systems, like the Advanced Spaceborne Thermal Emission Reflection Radiometer (ASTER) on "Terra" and Landsat-8TIRS etc. have limited lifetimes and/or do not achieve VISIRSAT's thermal resolution (dT $-0,3 \mathrm{~K}$ ).

The former Bi-spectral InfraRed Detection (BIRD) satellite demonstrated the low Earth orbit detection and quantitative analysis of even quite small high-temperature events (HTE), such as wildfires and volcanic outbreakes, more than ten years ago (Briess et al., 2003). BIRD's co-registered MIR, TIR and NIR imagery - with a spatial resolution of $200 \mathrm{~m}$ - were successfully used also for the derivation of Fire Radiative Power (FRP), which correlates to combustion rate (Wooster et al., 2003, Zhukov et al., 2006).
Since BIRD ceased to take regular imagery (in 2004), several studies on future dedicated IR land observation sensors have been conducted for ESA, for instance, a Study on Scientific Assessment of Space-borne High Temperature Event Observing Mission Concepts (ECOFIRE) (Oertel et al., 2005), and the Dual-use European Security IR Experiment 2008 (DESIREX 2008) (Sobrino et al., 2009).

BIRD was followed by the FireBird mission of the German Aerospace Centre (DLR), which is based on a BIRD-type sensor. The first of two FireBird sensors was piggy-back launched into a sun-synchronous orbit on 22 July 2012 on board of the German small satellite TET-1, and is regularly observing fires since autumn, 2013. TET-1 will be followed by a second satellite with similar specifications, BIROS, to complete the FireBird mini-constellation. FireBird provides FRP maps of actively burning fires derived at a spatial resolution better than $250 \mathrm{~m}$ - together with the estimation of effective fire temperature and spatial extent even for small fire events - many of which cannot be detected and/or characterized by existing and planned coarse resolution IR sensor systems (Ruecker et al., 2012). FireBird FRP is used to estimate combustion rate, and in conjunction with data from medium resolution sensors, to estimate greenhouse gas emissions from

\footnotetext{
* Corresponding author
} 
fires. Figure 1 shows a TET-1 FRP map of fires in a protected area in central Brazil.

The FireBird sensors also provide IR imagery of the ambient Earth surface. However, the MIR- and TIR- imagery data from FireBird is only "bi-spectral", i.e. with one band centred at 3.7 and one at $9.2 \mu \mathrm{m}$, which is not optimal for land surface temperature estimation.
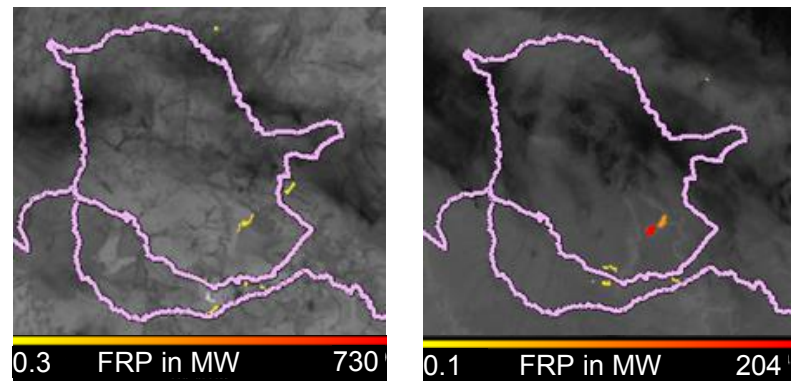

Figure 1. FireBird FRP map of fires in a protected area in central Brazil (purple outline) obtained by TET-1 on 2014/10/17 at local noon (left) ad near midnight (right). The

FRP value of the fire clusters is colour coded - see scale.

\section{LAND SURFACE TEMPERATURE (LST) AND TEMPERATURE EMISSIVITY SEPARATION (TES)}

Land surface temperature (LST) is important for understanding energy fluxes between earth's surface and the atmosphere from the local to the global scale (Sobrino et al., 2004, Anderson et al., 2008, Li et al., 2013, Merchant et al., 2013). With recent climate change the averaged radiation flux intensity has reached a value of $1.72 \mathrm{~W} \cdot \mathrm{m}-2$ ("radiative forcing") and has thereby increased the upwelling infrared longwave radiation (Solomonm et al., 2007). An accurate determination of the LST is necessary to derive information about space-time variations of the earth's radiation balance and for an improved understanding of the factors influencing climate change.

Acquiring more precise LST data is also crucial for environmental research (Kerr et al., 2000):

- Monitoring agricultural or forest areas and natural vegetation

- Monitoring urban heat islands

- Detecting precursors of volcanic eruptions

Estimating evapotranspiration.

In addition, the data of the MIR/TIR bands can be applied to determining the mass balance of glaciers by monitoring the ice surface temperature (IST) or by deriving the sea surface temperature (SST), to investigate the complex ocean currents to identify temperature changes and shifting flow patterns (Biastoch and Boning, 2013).

However, limitations of the spatial, temporal and spectral (especially for MIR/TIR bands) resolution of current satellite sensors remain a major challenge for obtaining sufficient, accurate physical data. Depending on retrieval methods, the estimated error range of LST products is between 0.5 Kelvin and several Kelvin. If the dynamics of land surface emissivity (LSE) are not considered, the uncertainty increases significantly and can reach up to 6 Kelvin ( $\mathrm{Li}$ et al., 2013). To include the dynamic LSE, NDVI-based emissivity methods or temperature emissivity separation (TES) methods can be used (Gillespie et al., 1996, Gillespie et al., 1998), which require a mor spectral bands in the thermal region. Especially for land surfaces, it is therefore necessary to advance the development of satellitebased observation techniques of LST, with improved spatial resolution and a corresponding repetition rate, to suitably reproduce space-time dynamics of land surface phenomena.

\section{INFRARED OBSERVATION GAPS AND RELATED} CONVOY MISSION CONCEPT CANDIDATES

Land applications were discussed at the ESA Sentinel Convoy for Land Applications workshop held at ESA ESTEC in November 2011 (Remedios et al., 2012) with regard to mid- and thermal infrared observations for major land applications (see table 1).

\begin{tabular}{|c|c|c|}
\hline Application & $\begin{array}{l}\text { Earth observation } \\
\text { variable(s) }\end{array}$ & $\begin{array}{l}\text { IR observation } \\
\text { gap }\end{array}$ \\
\hline $\begin{array}{l}\text { Carbon Cycle } \\
\text { - fire sensing }\end{array}$ & $\begin{array}{l}\text { Fire Radiative Power } \\
\text { (FRP) }\end{array}$ & $\begin{array}{l}\sim 250 \mathrm{~m} \\
\text { resolution } \\
\text { MIR/TIR - to } \\
\text { sample smaller } \\
\text { fires }\end{array}$ \\
\hline $\begin{array}{l}\text { Surface } \\
\text { energy } \\
\text { balance }\end{array}$ & $\begin{array}{l}\text { Land Surface } \\
\text { Temperature (LST) }\end{array}$ & \multirow{3}{*}{$\begin{array}{l}<100 \mathrm{~m} \\
\text { resolution multi- } \\
\text { spectral TIR, to } \\
\text { account for } \\
\text { spectral } \\
\text { variations in } \\
\text { emissivity }\end{array}$} \\
\hline Water cycle & LST, Soil moisture & \\
\hline $\begin{array}{l}\text { Human } \\
\text { population } \\
\text { dynamics } \\
\end{array}$ & $\begin{array}{l}\text { Urban LST, urban } \\
\text { emissivity }\end{array}$ & \\
\hline \multirow[t]{2}{*}{ Volcanoes } & $\begin{array}{l}\text { Thermal anomalies, } \\
\text { pre-eruptive } \\
\text { precursors \& SO2 } \\
\text { degassing plumes }\end{array}$ & $\begin{array}{l}<60 \mathrm{~m} \text { resolution } \\
\text { multi-spectral } \\
\text { MIR/TIR }\end{array}$ \\
\hline & $\begin{array}{l}\text { Lava thermal } \\
\text { characteristics and } \\
\text { mapping }\end{array}$ & $\begin{array}{l}<30 \mathrm{~m} \text { resolution } \\
\text { multi-spectral } \\
\text { SWIR/MIR/TIR }\end{array}$ \\
\hline
\end{tabular}

Table 1. Science and operational gaps in mid- and thermal infrared observation for main land applications

The Executive Summary and Final Report (Regan, 2014) of the "1st International Earth Observation Convoy and Constellation Workshop" - conducted at ESA ESTEC in October 2013 highlighted several specific convoy concepts. One of these highlighted convoy concepts offers higher spatial resolution between 30 meters and 250 meters in the thermal infrared spectral range. Important mission aspects for this specific convoy concept are (Regan, 2014):

- Measurements in the thermal infrared spectral range are needed for numerous Earth Science domains. Current in-orbit TIR instruments (e.g. Landsat-8-TIRS, Aqua/Terra-MODIS, Terra-ASTER etc.) all have limited lifetimes and if replacements are not launched then there will be a strong possibility of a data gap later this decade.

- Multiple TIR channels are needed to separate emissivity and temperature.

- Mid infrared and thermal infrared are needed to measure fires and thermal hot spots (with additional visible channels for context).

- To measure thermal anomalies a high dynamic range is required to mitigate detector saturation.

- There is cross cutting science between land and atmospheric sounding communities regarding infrared imagery. 
Flying a thermal infrared imager with Sentinel-2 was highlighted.

\section{MEASUREMENT AND INSTRUMENT REQUIREMENTS FOR A HIGH RESOLUTION THERMAL INFRARED RADIOMETER}

A detailed and critical analysis of the measurement and instrument requirements was conducted for the thermal Infrared Radiometer of the planned Hyperspectral InfraRed Imager (HyspIRI) (Hook et al., 2011).

It appears that the science and operational infrared observation gaps identified in (Remedios et al., 2012) can be nearly completely closed, if the MIR/TIR measurement and instrument requirements defined for the Thermal Infrared Radiometer of HyspIRI (Hook et al., 2011) would be fulfilled.

Furthermore, the DESIREX campaign of 2008 investigated requirements for urban heat island monitoring (Sobrino et al., 2009). The study came to the conclusion that multispectral or hyper-spectral thermal IR data are required at spatial resolutions well below $100 \mathrm{~m}$. The "coincidence" of the gaps identified in Remedios et al. (2012) and requirements from Hook et al. (2011) are summarised in Table 2 of the "Infrared Imaging Sensor Suite - Mission (IRIS-M)" proposal paper (Oertel et al., 2013). The main measurement and instrument requirements to the VISIR-SAT high spatial and spectral resolution multispectral thermal IR radiometer rely also on the figures given in Table 2 of the IRIS-M proposal (Oertel et al., 2013).

\section{APPLICATION OF DATA FUSION}

An example of Land Surface Temperature (LST) observation with the Airborne Hyper-spectral Scanner (AHS) over Madrid is given in Figure 2. The aggregation has been made from the AHS overpass at $4 \mathrm{~m}$ spatial resolution on the 28th June at 21:44 h. Ten images have been generated, with spatial resolutions of $10 \mathrm{~m}, 20 \mathrm{~m}, 30 \mathrm{~m}, 40 \mathrm{~m}, 50 \mathrm{~m}, 100 \mathrm{~m}, 200 \mathrm{~m}, 300$ $\mathrm{m}, 500 \mathrm{~m}$ and $1000 \mathrm{~m}$ (Sobrino et al., 2012). For instrumental reasons, MIR and TIR imagers typically operate at coarser spatial resolution than do visible (VIS) and near infrared (NIR) band sensors on the same satellite platform, especially in case of a small satellite.

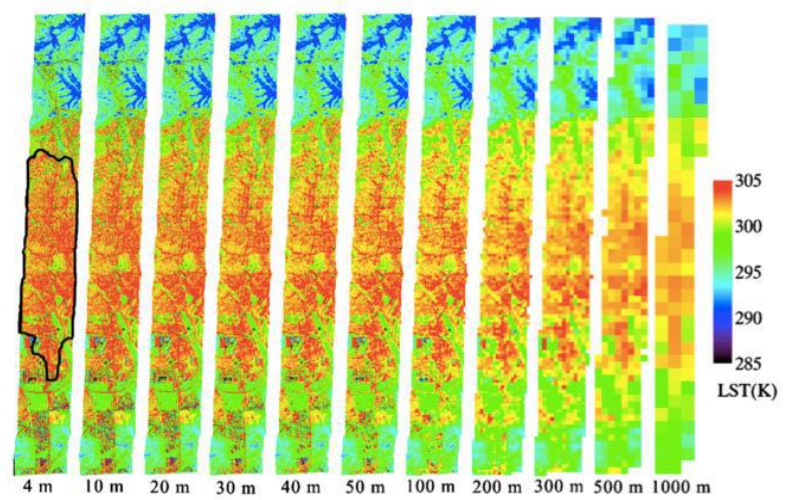

Figure 2. Land Surface Temperature (LST) observations with different spatial resolutions over Madrid. The leftmost panel (4 $\mathrm{m}$ resolution) shows the outline of Madrid's municipal

boundaries in black (from Sobrino et al., 2009).

For space-borne LST observations, to be conducted by the multi-spectral thermal imager of VISIR-SAT with $\sim 90 \mathrm{~m}$ spatial resolution, data fusion methods shall be implemented to enhance the spatial resolution up to $30 \mathrm{~m}$. This kind of "thermal sharpening" may use, fortunately, an inverse relationship between LST and Vegetation Indices (VI's). One such possible data fusion method, the Multi-sensor Multi-resolution Technique (MMT), is well developed and tested over agricultural areas for multi- and hyper-spectral imaging data coregistered at day time with different spatial resolutions (Zhukov et al., 1999).

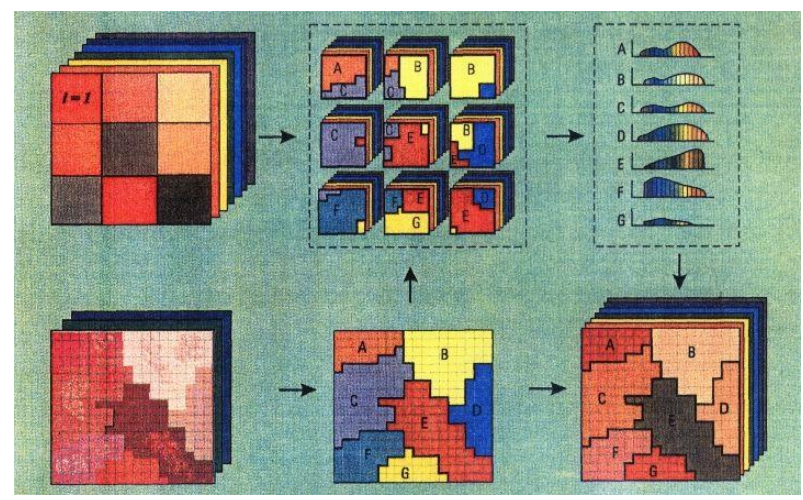

Figure 3. Principal processing scheme of the Multi-sensor Multi-resolution Technique (MMT) (from Zhukov et al., 1999)

Figure 3 illustrates the MMT Principal scheme, with the following elements:

(1) a multi-spectral scene fragment from the spatial higher resolution VIS/NIR camera (the "classifying instrument") - in the lower row on left hand site,

(2) the classification map obtained from the multi-spectral VIS/NIR data - in the middle of the lower row,

(3) a hyper-spectral or multi-spectral scene fragment from the lower spatial resolution sensor (the "measuring" instrument) - in the upper row on left hand site,

(4) an overlay of the classification result on the coarser resolution scene pixels of the measuring instrument - in the middle of the upper row,

(5) the classification result for each class (A-G) in the hyperspectral domain - in the right hand site of the upper row, and

(5) the unmixed, or "fused", hyper-spectral (or multi-spectral) scene fragment with high spatial resolution borders between the classes - in the right hand site of the lower row.

\section{VISIR-SAT MISSION OBJECTIVES}

The VISIR-SAT mission has the following main objectives: to close the infrared observation gaps identified by the ESA Sentinel Convoy for Land Applications workshop in November 2011 (Remedios et al., 2012) - as summarized in Table 1 ,

- to fulfil most of the measurement and instrument requirements specific convoy concept on "High resolution thermal infrared $(<60-250 \mathrm{~m})$ " as highlighted by Regan (2014), and

- to allow spatial enhancement of the multi-spectral MIR/TIR data by higher spatial resolution VIS/NIR data using the MMT technique for data sets obtained at day time.

The VISIR-SAT mission targets to provide:

a) Higher spatial resolution $(\sim 80 \mathrm{~m})$ multi-spectral imaging TIR data (up to 6 bands between 8 and $12 \mu \mathrm{m}$ ) \& 
imaging MIR data ( 1 or 2 bands at $4 \mu \mathrm{m})$, and supplementary,

b) High spatial resolution $(20$ - $30 \mathrm{~m})$ multi-spectral imaging data with two bands in the visible (VIS, at 0.5 and $0.6 \mu \mathrm{m}$ ) and one band in the near infrared (NIR, at $0.86 \mu \mathrm{m})$.

The main purpose of the VIS-NIR data is to provide a high resolution $(\sim 30 \mathrm{~m})$ classification map necessary for the application of the Multi-sensor Multi-resolution Technique (MMT) to the MIR/TIR data records of VISIR-SAT acquired at day time. The application of the MMT to the VISIR-SAT data sets requires the knowledge of the optical co-alignment of the instrument bands with an accuracy $<0.2$ of the ground sampling distance (GSD) of the coarser resolution ("measuring") instrument (Zhukov et al. 1999). The compliance of this requirement is feasible with "state of the art" attitude and orbit control systems (AOCS).

\section{EXPECTED VISIR-SAT DATA PRODUCTS}

Data records from VISIR-SAT will allow to retrieve spatially high to medium resolved EO imaging data products, including EO variables and Essential Climate Variables (ECV`s), such as:

A) Variables for normal temperature phenomena (NTP): Land Surface Temperature (LST), including urban surface temperature, surface emissivity, including urban emissivity, and soil moisture (SM).

LST and SM are strongly related to hydrology and land surface energy fluxes as well as to vegetation dynamics, including plant evapotranspiration, water stress and irrigation needs relevant for food production in water-scarce agricultural regions and sustainable management of water resources and, generally, the consumptive use of global freshwater.

B) Variables for high temperature events (HTE):

The Fire Disturbance ECV`s: Burned Area, Active Fire (location) and Fire Radiative Power (FRP), which can be used for fire emission assessments.

Beyond these Fire Disturbance ECVs, the following additional fire attributes will be obtained from the VISIR-SAT data: fire effective temperature, fire effective area, fire line length, and fire line radiative strength, which all are key parameters for fire management and fire ecology (Ruecker et al., 2012).

To predict and mitigate earthquake and volcanic hazards through detection of transient thermal phenomena, the following EO variables will be derived from VISIR-SAT data: volcanic pre-eruptive thermal anomalies and thermal anomalies on fumarole fields, thermal characteristics of lava flows, such as: crust and lava temperature, and volcanic ash emissions.

\section{VISIR-SAT SENSOR DESIGN BASE LINE}

The key instrument of VISIR-SAT is its multi-spectral MIR/TIR sensor. Figure 4 shows the draft design concept of the VISIR-SAT multi-spectral MIR/TIR push-broom sensor's optics and focal plane.

The optics of the multi-spectral MIR/TIR imager will have four lenses and a plane entrance filter. This optics will illuminate via the entrance window of the detector dewar - the focal plane of an Integrated Detector Cooler Assembly (IDCA). A spectral filter plate with two stripped MIR filters and six stripped TIR filters will be placed with $0.2 \mathrm{~mm}$ distance in front of a Mercury Cadmium Telluride (MCT) megapixel matrix detector with $1280 \times 1024$ elements and with a $15 \mu \mathrm{m}$ pitch in both directions (Ziegler et al., 2012). The lens and the detector array are designed to cover the wavelength region from 3.5 to $12 \mu \mathrm{m}$. For an assumed satellite altitude of $800 \mathrm{~km}$ over ground, this compact lens - detector combination will provide a spatial resolution of $80 \mathrm{~m}$ and a swath width of $\sim 100 \mathrm{~km}$ for the MIR and TIR bands of VISIR-SAT.

The multi-spectral VIS-NIR sensor of VISIR-SAT will also be a push-broom sensor. Similar to the VISIR-SAT MIR/TIR sensor it will also use lens optics and a matrix detector array. A filter plate with stripped spectral filters for VIS and NIR bands will be mounted behind the entrance lens directly in front of a Silicon Charge Coupled Device (Si-CCD) matrix detector array (such, as the KAI 16070 type from "Truesense", which comprises four array segments).

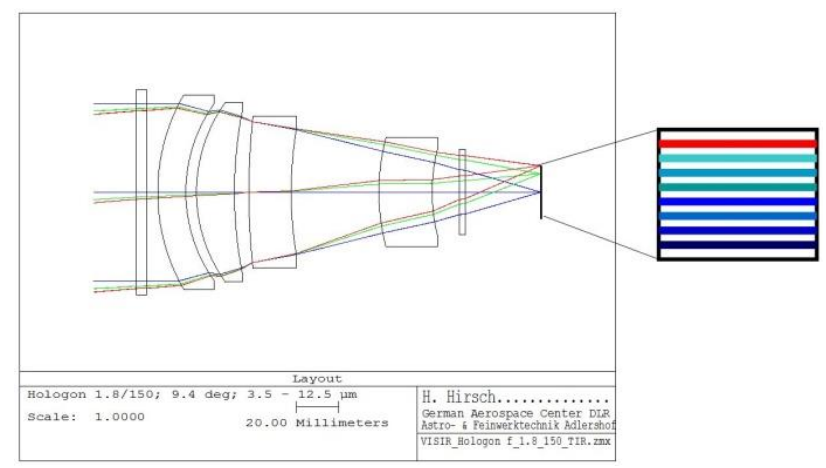

Figure 4. Design concept of the VISIR-SAT multi-spectral MIR/TIR sensor's optics and focal plane with a Hologon optics for a wavelength region $3.5-12.5 \mu \mathrm{m}$ and the schematically shown focal plane on the right hand site with a stripped filter arrangement ( 2 for MIR and 6 for TIR) - to be mounted on a cooled Mercury Cadmium Telluride (MCT) detector matrix

The multi-spectral MIR/TIR imaging radiometer and the multispectral VIS-NIR imager of VISIR-SAT will be mounted on one thermally very stable payload platform ("optical bench") together with the star sensor(s) of the Attitude Orbit Control System (AOCS) of the satellite bus to assure an exact knowledge of the EO sensor's orientation.

Preliminary physical parameters of the VISIR-SAT multispectral sensor instruments are given in Table 2.

\section{VISIR-SAT BUS DESIGN CONCEPT}

The VISIR-SAT satellite bus development will be based on the experience obtained from the German micro-satellite missions BIRD, TET-1, and BIROS

The BIRD and TET-1 satellites were piggy back launched, and BIROS will be piggy back launched.

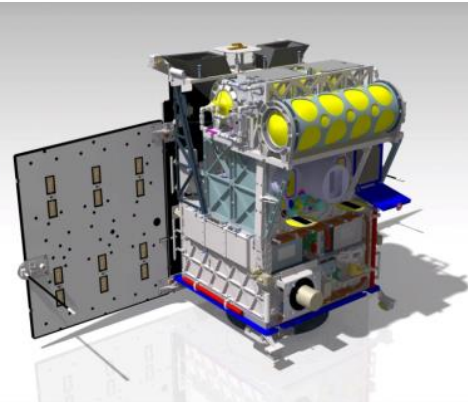

Figure 5. The BIROS satellite, planned to be piggy back launched in 2015 (from Halle et al. 2014) 
Figure 5 shows the BIROS satellite which shall be piggy back launched end of 2015. The BIROS bus is equipped with a cold gas propulsion system and a 3 axis set of High Torque Wheels (HTW) (Halle et al., 2014). The HTW set will allow a $30^{\circ}$ turn of the BIROS's sensors Line of Sight (LoS) within $10 \mathrm{sec}$.

\begin{tabular}{|c|c|c|}
\hline & $\begin{array}{l}\text { VIS-NIR multi- } \\
\text { spectral imager }\end{array}$ & $\begin{array}{l}\text { MIR/TIR multi- } \\
\text { spectral imaging } \\
\text { radiometer }\end{array}$ \\
\hline $\begin{array}{l}\text { Wavelength } \\
\text { bands }\end{array}$ & $\begin{array}{l}\text { Two VIS at } 0.5 \& \\
0.6 \mu \mathrm{m} \text { and one } \\
\text { NIR at } 0.8 \mu \mathrm{m}\end{array}$ & $\begin{array}{l}\text { Two MIR at } 3.6 \& 3.9 \\
\mu \mathrm{m} \text {, and six TIR within } \\
8.5-12.0 \mu \mathrm{m}\end{array}$ \\
\hline Focal length & $296 \mathrm{~mm}$ & $150 \mathrm{~mm}$ \\
\hline $\begin{array}{l}\text { Field of View } \\
\text { (FOV) }\end{array}$ & $\sim 9,4^{\circ}$ & $9.4^{\circ}$ \\
\hline F-Number & $\sim 4.0$ (tbd.) & 1.8 \\
\hline Detector type & $\begin{array}{l}\mathrm{Si} \text { - CCD - matrix } \\
\text { array (tbd.) }\end{array}$ & MCT - matrix array \\
\hline Detector cooling & Passive, $\sim 290 \mathrm{~K}$ & Stirling, $\sim 80 \mathrm{~K}$ \\
\hline $\begin{array}{l}\text { Detector } \\
\text { element pitch }\end{array}$ & $7.4 \mu \mathrm{m} \times 7.4 \mu \mathrm{m}$ & $15 \mu \mathrm{m} \times 15 \mu \mathrm{m}$ \\
\hline $\begin{array}{l}\text { Number of } \\
\text { detector } \\
\text { elements }\end{array}$ & $\begin{array}{l}4864 \times 3232 \\
\text { (tbd.) }\end{array}$ & $1280 \times 1024$ \\
\hline Quantisation & 14 bit & $\begin{array}{l}14 \text { bit (+ variable int. } \\
\text { times) }\end{array}$ \\
\hline Ground pixel & $20 \mathrm{~m}^{*}$ & $80 \mathrm{~m}^{*}$ \\
\hline Swath width & $103 \mathrm{~km}^{*}$ & $103 \mathrm{~km}^{*}$ \\
\hline $\begin{array}{l}\text { In-flight- } \\
\text { calibration }\end{array}$ & $\begin{array}{l}\text { Not foreseen } \\
\text { (tbd.) }\end{array}$ & By two blackbodies \\
\hline Estimated mass & $\sim 8-10 \mathrm{~kg}$ & $\sim 40 \mathrm{~kg}$ \\
\hline $\begin{array}{l}\text { Power } \\
\text { consumption }\end{array}$ & $\sim 5-10 \mathrm{~W}$ (tbd.) & $\sim 50 \mathrm{~W}$ (tbd.) \\
\hline
\end{tabular}

$*$ from $800 \mathrm{~km}$ altitude

Table 2: Preliminary physical parameters of the VISIR-Sat sensor instruments

\begin{tabular}{|l|c|}
\hline Parameter & \multicolumn{1}{|c|}{$\begin{array}{l}\text { Preliminary } \\
\text { Specification }\end{array}$} \\
\hline $\begin{array}{l}\text { Estimated satellite envelope } \\
\text { (length x width x height) }\end{array}$ & $650 \times 550 \times 1000 \mathrm{~mm}^{3}$ \\
\hline $\begin{array}{l}\text { Estimated payload envelope } \\
\text { (length x width x height) }\end{array}$ & $600 \times 500 \times 600 \mathrm{~mm}^{3}$ \\
\hline $\begin{array}{l}\text { Mass of VISIR-SAT spacecraft } \\
\text { bus, including propulsion } \\
\text { system }\end{array}$ & $\sim 80-90 \mathrm{~kg}$ \\
\hline Payload mass & $\sim 50-60 \mathrm{~kg}$ \\
\hline Type of attitude stabilisation & $\sim 2$ arcmin \\
\hline Satellite pointing accuracy & $\sim 10$ arcsec \\
\hline Satellite pointing knowledge & $\sim 10 \mathrm{~m}$ \\
\hline $\begin{array}{l}\text { Satellite on-orbit position } \\
\text { knowledge }\end{array}$ & $\sim 100 / 250 \mathrm{~W}$ \\
\hline $\begin{array}{l}\text { Payload power allocation, } \\
\text { average / peak }\end{array}$ & \\
\hline
\end{tabular}

Table 3: Preliminary VISIR-SAT satellite bus specifications
Similar to BIROS, VISIR-SAT will have an Ammonium DiNitramide (AND) propulsion system for "orbit maintenance" and for de-orbiting at the end of mission. Also a triple of High Torque Wheels (HTW) will be used in the VISIR-SAT bus to support the Attitude and Orbit Control System (AOCS) especially for agile pointing of the sensors LoS. VISIR-SAT shall also be suited for piggy back launch. Table 3 shows preliminary VISIR-SAT satellite bus specifications.

An important recommendation of the Food and Agriculture Organisation (FAO) and the Group of Earth Observations (GEO) (Justice et al., 2007) states:

"Within the next 5 to 10 years, the space agencies should develop and implement the next generation of operational moderate resolution sensing systems, working in concert to provide a truly integrated system, acquiring and providing global coverage of $60-10 \mathrm{~m}$ cloud free imagery every 5-10 days."

This means for the higher resolution thermal infrared mission (< $60-250 \mathrm{~m}$ ) highlighted in Regan (2014) and, consequently, also for VISIR-SAT, that it will be necessary to secure an effective coverage time of $5-10$ days ${ }^{1}$. To meet this recommendation in the optical and IR bands, it is necessary to have, either

- a constellation of several satellites (similar to Sentinel-2 $\mathrm{A}+\mathrm{B})$

- a wide swath (> 600km) sensor system, or

- high agility of a single satellite \& sensor system, with intelligent pointing of the sensors Line of Sight $(\mathrm{LoS})$ in a wide Field of Regard (FoR) as illustrated in Figure $6^{2}$. In this example, the LoS of the push broom sensor is moving forward with a speed of $\sim 27 \mathrm{~km} / \mathrm{s}$, which is approximately four times higher than the speed of the satellite over ground $(6.6 \mathrm{~km} / \mathrm{s})$.

This high agility will be possible for VISIR-SAT due to the use of:

(a) cooled MCT matrix detector array in combination with stripped filters in the multi-spectral MIR/TIR sensor (allowing fast sampling with overlaps also for supplementary data binning), and

(b) the HTW as the key actuators to enable fast and agile pointing of the sensor's LoS.

The area covered by the sensor in Figure 5 is approximately two times larger than the area which the sensor would cover in a "classic" push broom mode, where the sensors LoS is moving forward with the speed of the satellite over ground $(6.6 \mathrm{~km} / \mathrm{s})$.

\section{POTENTIAL CONVOY AND CONSTELLATION MISSION OPTIONS FOR VISIR-SAT}

There are several interesting convoy and/or constellation mission options for VISIR-SAT:

The high agility of VISIR-SAT - as illustrated in Figure 5 - will make it an ideal candidate to be flown in convoy with Sentinel-

1 The effective coverage time represents the temporal periodicity of systematic acquisition of a given area with cloud cover (excluding thin cirrus if thin cirrus can be detected and their effect corrected) below a specific threshold and possibly under different viewing conditions (ESA Sentinel-2 Team, 2007).

2 Intelligent pointing may be, for instance, the use of information on the cloud cover and cloud free regions for the pointing of the sensors Line of Sight $(\mathrm{LoS})$ in a wide Field of Regard (FoR). 
$2 \mathrm{~A}+\mathrm{B}$ satellites $(\mathrm{S}-2 \mathrm{~A}+\mathrm{B})$ to complement their Multi-Spectral Imagers (MSI's) which are providing high resolution data in the VIS-NIR-SWIR reflective spectral region.

The intelligent and agile pointing of the LoS of VISIR-SAT's sensors, as illustrated by Figure 5, will allow IR data acquisitions within the $580 \mathrm{~km}$ combined swath width of S$2 \mathrm{~A}+\mathrm{B}$. The IR-companion would conduct data records nearly simultaneously to MSI acquisitions of $\mathrm{S}-2 \mathrm{~A}+\mathrm{B}$ of $\mathrm{S}-2 \mathrm{~A}+\mathrm{B}$ at $\sim$ 10:30 h local time. Furthermore, the IR companion could be "switched on" at $\sim 22: 30 \mathrm{~h}$ local night time. The higher spatial resolution IR data products from this possible Sentinel-2A+B IR-companion could be used to retrieve EO variables for normal temperature phenomena and for HTE applications as explained in detail in chapter 6 of this paper.

The combination of the day time data from $\mathrm{S}-2 \mathrm{~A}+\mathrm{B}$ and their IR companion VISIR-SAT would furthermore allow obtaining data sets close to that of the current ASTER mission.

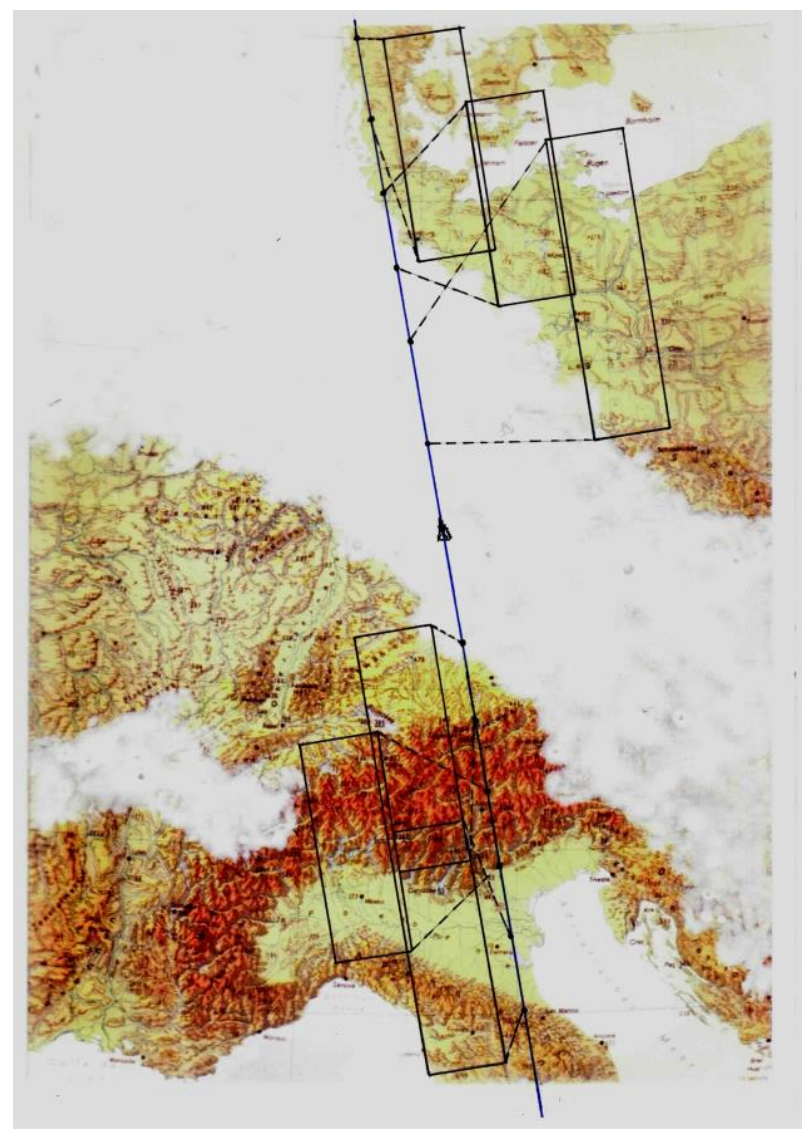

Figure 6. Illustration of intelligent and agile pointing of the line of Sight of a push broom sensor in a partly cloud-covered scene

An agile VISIR-SAT, flown in convoy with Sentinel-3 (S-3), would complement the low spatial but high temporal resolution VIS-to-LWIR data of the S-3 Sea and Land Surface Temperature Radiometer (SLSTR), especially its land and fire data products (Wooster et al., 2012). In particular, VISR-SAT as an IR-companion of S-3 can be used for the validation of the FRP products from Sentinel-3, which has a much higher fire detection threshold.

It seems further reasonable to consider several VISIR-SAT type IR-companions in constellation with Sentinel-2 and/or Sentinel3 , for instance: (a) one such IR micro-satellite in convoy with S-
2 and/or S-3 (with Local Times of Descending Node /LTDN/ at $10: 30 \mathrm{~h}$ or $10: 00 \mathrm{~h}$, respectively), and (b) another IR microsatellite on an orbit with a LTDN at noon or at $\sim 13: 30 \mathrm{~h}$, when both plant evapotranspiration and wildfire activity are at maximum.

Due to the high variability of wildfires, additional sampling of the diurnal fire cycles and additional co-registrations with other FRP-observing satellites, such as Suomi NPP, Aqua, Terra, Meteosat-X, GOES-X and others would be advantageous. Therefore, VISIR-SAT could be used as a transfer standard between the various space-borne thermal fire observations. This could be achieved, for instance, by a drifting orbit of VISIRSAT.

Generally, the VISIR-SAT fire data shall be used for the Copernicus Atmosphere Service (CAS) projects (i) to statistically adjust the emissions estimates, and (ii) exploit observations of larger fires to provide an extensive validation of the FRP products obtained from "fire capable" moderate-tocoarse spatial resolution missions currently operating and those planned for the near future (Oertel et al., 2013).

\section{ACKNOWLEDGEMENTS (OPTIONAL)}

The authors would like to thank the Firebird project form the German Aerospace Center for providing FRP data and for maintaining a continuous dialogue on scientific exploration of data. Our special gratitude is given to all scientists supporting the VISIR mission with various contributions for enhancing the science concept.

\section{REFERENCES}

Anderson, M. C. et al. (2008), A thermal-based remote sensing technique for routine mapping of land-surface carbon, water and energy fluxes from field to regional scales, Remote Sensing of Environment 112, No. 12, pp 4227-4241.

Biastoch, A. and Böning, C. W. (2013), Anthropogenic impact on Agulhas leakage, Geophysical Research Letters 40, pp 11381143 .

Briess, K., Jahn, H., Lorenz, E., Oertel, D., Skrbek, W. \& Zhukov, B., (2003) Remote Sensing Potential of the Bi-spectral InfraRed Detection (BIRD) Satellite. Int. J. Remote Sensing, 24, pp 865-872.

ESA Sentinel-2 Team, (2007), GMES Sentinel-2 Mission Requirement Document, reference EOP-SM/1163/MR-dr.

Gillespie, A. et al. (1996), Temperature/emissivity separation algorithm theoretical basis document, Vol. 2.4, pp 1-64, Maryland, USA (NASA/GSFC).

Gillespie, A. et al. (1998), A temperature and emissivity separation algorithm for Advanced Spaceborne Thermal Emission and Reflection Radiometer (ASTER) images. IEEE Transactions on Geoscience and Remote Sensing 36, pp 11131126.

Halle, W., Baerwald, W., Raschke, C., Terzibaschian, T., (2014), The DLR-Satellite BIROS in the FireBIRD Mission, poster-proceedings of the " $4 \mathrm{~S}$ "-Symposium, Porto Petro, Mallorca (E), see http://congrexprojects.com/2014events/4S2014/home 
Hook, S. and HyspIRI Team, (2011), HyspIRI Experiences NASA Earth Sciences and Applications - Decadal Survey, California Institute of Technology. Jet Propulsion Laboratory, Presented at Sentinel Convoy for Land Applications Workshop, University of Leicester, UK.

Justice, C.O. and Becker-Reshef, I. (Eds), (2007) Report from the Workshop on Developing a Strategy for Global Agricultural Monitoring in the framework of Group on Earth Observations (GEO), UN FAO, July 2007, Geography Dept. University of Maryland, 66, pp.

Kerr, Y. H. et al. (2000), The Second of ESA's Opportunity Missions: The Soil Moisture and Ocean Salinity Mission SMOS, ESA Earth Observation Quarterly, Vol. 66, pp 18-25.

Li, Z.-L. et al. (2013), Satellite-derived land surface temperature, Current status and perspectives, Remote Sensing of Environment, Vol. 131, pp 14-17.

Merchant, C. J. et al. (2013), The surface temperature of the earth: steps towards integrated understanding of variability and change, Geoscientific Instrumentation, Methods and Data Systems. Discussion paper 3, pp 305-345.

Oertel, D., Ruecker, G., Hartmann, M., Hirsch, H., Kaiser, J. W., Walter, I., Wooster, M., Zhukov, B., (2013), Infrared Imaging Sensor Suite - Mission (IRIS-M), proceedings of the " 1 st international Earth observation Convoy and Constellation Workshop", ESA/ESTEC. Noordwijk, NL, see: http://congrexprojects.com/2013-events/13m12/programme, Proceedings / paper: 6B_1110_Oertel.

Oertel, D., Zhukov, B., Wooster, M., Tank, V., Lorenz, E., Holzer-Popp, T., Goldammer, J., Martinez, S., Siegert, F., et al., (2005), ECOFIRE - Study on Scientific Assessment of Spaceborne High Temperature Event Observing Mission Concepts, (ESA/ESTEC Contract 17690/30/NL/FF), Final Report, Berlin (Germany) German Aerospace Center (DLR).

Regan, A., (2014), Executive Summary and Detailed report on "1st International Earth Observation Convoy and Constellation Workshop", ESA/ESTEC, Noordwijk, NL, (ESA Ref. Nº: EOPSFT-2014-02-1789),

Remedios, J.J. Humpage, N. Ghent, D. (2012), Sentinel Convoy for Land Applications, Workshop Report \& Executive Summary, University of Leicester, UK.

Ruecker, G., Lorenz, E., Hoffmann, A., Oertel, D., Tiedemann, and Halle, W., (2012), Upcominig and prospective fire monitoring missions based on the heritage of the BIRD (Bispectral InfraRed Detection) satellite, IEEE International Geoscience and Remote Sensing Symposium (IGARSS) 2012.

Sobrino, J. A. et al. (2004), Land surface temperature retrieval from LANDSAT TM 5, Remote Sensing of Environment 90, No. 4, pp 434-440.

Sobrino, J. A., Bianchi, R., Paganini, M., Soria, G., JimenezMunzos, J., Oltra-Cario, R. et al. (2009), Dual-use European Security IR Experiment 2008 (DESIREX 2008), Final Report, Frascati (Italy), European Space Agency (ESA).

Sobrino, J.A., Oltra-Carrio, R., Soria, G., Bianchi, R. and Paganini, M. (2012), Impact of spatial resolution and satellite overpass time on evaluation of the surface urban heat Island effects, Remote Sensing of Environment, 117, pp 50-56.

Solomon, S., Qin, D., Manning, M. et al. (2007), Contribution of Working Group I to the Fourth Assessment Report of the
Intergovernmental Panel on Climate Change (IPCC), Summary for Policymakers.

Wooster, M., Xu, W. and Nightingale, T., (2012), Sentinel-3 SLSTR active fire detection and FRP product: Pre-launch algorithm development and performance evaluation using MODIS and ASTER datasets, Remote Sensing of Environment, 120, pp. 236-254.

Wooster, M., Zhukov, B., \& Oertel, D. (2003), Fire radiative energy release for quantitative study of biomass burning: derivation from the BIRD experimental satellite and comparison to MODIS fire products, Remote Sens. Environment, 86, pp 83107.

Zhukov, B., Lorenz, E., Oertel, D., Wooster, M., Roberts, G., (2006), Spaceborne detection and characterization of fires during the bi-spectral infrared detection (BIRD) experimental small satellite mission, Remote Sens. Environment, 100, pp 2951 .

Zhukov, B., Oertel, D., Lanzl, F. and Reinhäckel, G., (1999), Unmixing-based multi-sensor multi-resolution image fusion, IEEE Transactions on Geoscience and Remote Sensing, Vol. 37, No. 3, pp 1212-1226.

Ziegler, J., Bitterlich, H., Breiter, R., Bruder, M., Eich, D., Fries, P., Wollrab, R., Wendler, J., and Wenisch, J., (2012), Large-Format MWIR and LWIR Detectors at AIM, SPIE 870477 on Infrared Technology and Applications XXXIX Army Infrared R\&D I. 